Article

\title{
Allergen Skin Test Reactivity and Serum Total IgE Level in Adult Bronchial Asthmatic Patients
}

\author{
Parveen $\mathrm{T}^{1}$, Begum $\mathrm{N}^{2}$, Begum $\mathrm{S}^{3}$
}

Background : Asthma affects more than 100 million people worldwide. Increased morbidity is multifactorial and may include increased exposure to indoor allergens and environmental pollutants, overuse of beta- 2 agonist, underuse of anti-inflammatory mediators and limited education about health care. Allergy represents a specific alteration in biologic reactivity mediated by an immunologic mechanism and resulting in an adverse physiologic response. Objective : Some of the type of allergen's sensitivity by skin prick test and serum total IgE level were studied in adult asthmatic patients to observe their relationships. Methods : This study was carried out in the department of Physiology, Bangabandhu Sheik Mujib Medical University, Dhaka and Asthma center,Mohakhali, Dhaka from January 2005 to December 2005. Allergen skin prick tests (SPT) were done by Pepy's skin prick method and serum total IgE level by Enzyme Linked Immunosorbent Assay method on 30 asthmatic patients and 30 age and sex matched control subjects .Data were analyzed statistically by unpaired student's 't' test and Chi- squares test. Results: In this study, maximum numbers of asthmatic patients had positive SPT for dust mite which was followed by house dust and by cockroach. Frequency percentage for dust mite was significantly higher $(\mathrm{P}<0.05)$ than that of house dust and cockroach .It was also significantly higher in house dust than that of cockroach $(\mathrm{P}<0.001)$. The mean serum total IgE level was significantly higher $(\mathrm{P}<0.001)$ in asthmatic adults compared to that of healthy subjects. . On the other hand, the association between the positive skin prick tests of all allergens used in this study and elevated serum total IgE were not statistically significant $(\mathrm{P}>0.05)$. Conclusion : Therefore, it can be concluded that different allergens like, house dust, dust mite and cockroach are responsible for bronchial asthma in our country which can be detected by SPT. Thus it can be used for identification of type of actual allergens responsible for bronchial asthma which may be a useful measure for earlier detection of allergens and for hyposensitization or desensitization of that patients accordingly with those allergens.

Key words : Allergen, IgE , Bronchial asthma.

J Bangladesh Soc Physiol. 2009 June; 4(1): 1-6 For author affiliations, see end of text.

http://www.banglajol.info/index.php/JBSP

\section{Introduction :}

\section{A} llergic diseases like asthma, hay fever, allergic rhinitis are important cause of morbidity. Different observers found interrelationships among serum total IgE level and allergy skin prick test in general population .,2 Allergy represents a specific alteration in biologic

J Bangladesh Soc Physiol. 2009 June; 4(1): 1-6 reactivity mediated by an immunologic mechanism and resulting in an adverse physiologic response. Different investigators found that immediate hypersensitivity response in atopic individuals are generally mediated by IgE antibody which is the essential feature of the atopic state. ${ }^{3}$ In their study, most of them had shown that atopy is closely related to asthma. ${ }^{4}$ 


\section{Article}

Allergy plays a role in wide range of the disease, ranging from itching of the skin to potentially fatal condition such as bronchial asthma. ${ }^{5}$ Asthma due to allergy is often associated with a personal and family history of allergic diseases such as rhinitis, urticaria and eczema with positive wheal and flare skin reactions to injection of intradermal indoor and outdoor airborne allergens and associated with increased level of IgE in the serum . ${ }^{6}$

Allergens trigger asthmatic attacks in $60 \%$ to $90 \%$ of children and in $50 \%$ of adults. Approximately $75 \%$ to $90 \%$ of the patients with asthma had positive skin test results . Majority of allergens that provoke bronchial asthma are airborne. Again, asthma due to allergy is frequently seasonal. A non seasonal perennial form may results from allergy to house dust, house dust mite, animal danders ,feathers, molds and other allergens present continuously in the environment. ${ }^{6}$

Different investigators evaluated the relationships of allergy skin test reactivity and serum total IgE level to the respiratory symptoms. ${ }^{7}$ They observed the prevalence of symptoms of allergic diseases is increased in patients having increased serum total IgE concentration and it may be the strongest among asthma patients. Again, a high prevalence of positive skin reaction was reported in children with asthma but a very little information is available on the prevalence of immediate skin test reactivity in adult patients with asthma. It was shown that among 260 patients of adult asthma, $60 \%$ had reacted to house dust , 51\% reacted to house dust mite.$^{8-11 .}$

Again, it was observed that asthma is closely associated with age adjusted IgE level where as allergic rhinitis is most closely related to skin test positivity. ${ }^{12}$ Sensitization and exposure to indoor allergens act as risk factor for asthma. Therefore, housing condition play an important role in asthma, especially among lower socioeconomic population . ${ }^{13,14}$
Allergen Skin Test Adult Bronchial Asthmatic Patients

In our country, bronchial asthma is one of the common respiratory disease. Most of the cases are commonly treated without knowing the specific allergen which may be a causative factor for the disease. Again, both indoor and outdoor allergens may have some role in the occurrence of the disease. If specific allergens have been identified, which trigger asthma symptoms, better management of the patients can be done, which may lead them to a symptom-free life. In addition, identification of the specific allergens prior to the treatment may also help the physician in planning better management of the asthmatic patients especially by hyposensitization (Immunotherapy) .Furthermore, physician could monitor the effect of immunotherapy by repeating the skin test reactivity at regular interval and thereby adjust the dose of hypo sensitization to particular allergens accordingly . With this background, the present study has been designed to perform allergen skin test reactivity with various indoor allergens in adult asthmatic subjects in order to find out the common variety and to observe serum total IgE level . In this study the association among skin test reactivity and serum total IgE level were also observed in the same group of patients.

The study also aimed to utilize the findings of skin prick test as background information for the clinicians in desensitizing the common allergens present in the asthmatic patients in our country and better management of bronchial asthma and also to create awareness among this group of patients so that they can take early and regular treatment .

\section{Methods}

The present observational study was done in the department of Physiology, Bangabandhu Sheik Mujib Medical University, Dhaka and Asthma center, Mohakhali, Dhaka from January 2005 to December 2005. In this study a total

J Bangladesh Soc Physiol. 2009 June; 4(1): 1-6 
number of 60 subjects with age range of 20 to 40 years of both sexes were included, of whom 30 apparently healthy and 30 asthmatic adult subjects were included, in group A (Control ) and in group B (Asthmatic patients ) respectively.

Detailed procedures and objectives of the study were explained to the subjects and their written informed consents were taken before performing the study. Sociodemographic data including age ,sex, family history ,monthly income were taken. Allergic history regarding different types of allergens including food were also taken .Both physical and clinical examinations were done for each subjects and all the information were recorded in a prefixed data sheet.

Detailed procedure about the skin prick tests were briefed to all the asthmatic patients and the tests were performed with the help of different allergens ( House dust, dust mite and Cockroach ). Assurance was given to the patients that the study would not bring any health hazards. Blood samples were collected for estimation of serum total IgE both in asthmatic patients and also in healthy subjects. Allergen skin prick tests were done by Pepy's skin prick method and serum total IgE level were measured by Enzyme Linked Immunosorbent Assay method. Data were analyzed statistically by unpaired student's ' $\mathrm{t}$ ' test and Chi-squares test using SPSS version 12.

\section{Results}

Anthropometric details of all subjects and sex distribution are shown in table I and figure 1. Both groups are matched for age, sex and BMI.

Results of skin prick tests with three different allergens are shown in Figure 2. Maximum percentage of asthmatic patients showed positive reaction with dust mite which was statistically significant $(\mathrm{P}<0.001)$.

J Bangladesh Soc Physiol. 2009 June; 4(1): 1-6
Table I: Age, sex , height, weight and BMI in different study groups ( $\mathrm{n}=60$ ).

\begin{tabular}{lccc}
\hline Parameters & $\begin{array}{c}\text { Group A } \\
\text { Mean } \pm \text { SD } \\
(\mathrm{n}=30)\end{array}$ & $\begin{array}{c}\text { Group B } \\
\text { Mean } \pm \text { SD } \\
(\mathrm{n}=30)\end{array}$ & $\begin{array}{c}\text { P } \\
\text { value }\end{array}$ \\
\hline Age(Years) & $27.77 \pm 5.75$ & $29.10 \pm 6.053$ & 0.50 ns \\
Height $(\mathrm{cm})$ & $159.63 \pm 5.461$ & $160.57 \pm 3.910$ & $0.10^{\text {ns }}$ \\
Weight $($ Kg) & $61.73 \pm 7.488$ & $63.93 \pm 6.933$ & $0.50^{\text {ns }}$ \\
BMI & $24.13 \pm 1.71$ & $24.7 \pm 4.02$ & $0.10^{\text {ns }}$ \\
\hline
\end{tabular}

Group A: Apparently healthy adults (control )

Group B: Adults suffering from mild intermittent asthma (experimental)

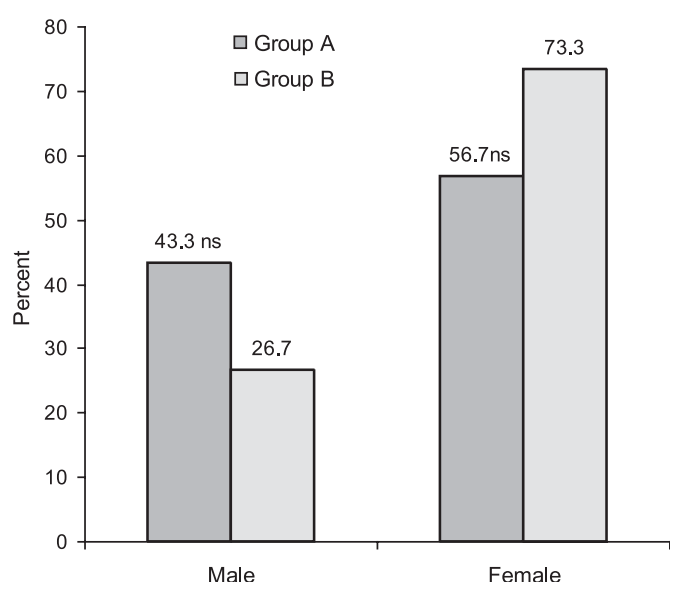

Figure 1. Showing distribution of the subject by sex.$(n=60)$

Results of serum total IgE of all subjects are shown in figure-3. The mean $( \pm S D)$ serum total IgE level was significantly $(\mathrm{P}<0.001)$ higher in asthmatic patients than that of control subjects.

Again distribution of all the subjects by serum total IgE level are presented in table-II. Serum total Ig E level (>100IU/ml ) was observed in 80\% of asthmatic patients and in $6.7 \%$ of healthy subjects. The difference was statistically significant $(\mathrm{P}<0.001)$. 
Table II. Distribution of the subjects by serum total IgE Level in different study groups $(n=30)$ :

\begin{tabular}{|c|c|c|c|c|c|c|}
\hline \multirow[t]{3}{*}{ Serum total IgE level IU/ml } & \multirow[t]{3}{*}{$\mathrm{df}$} & \multicolumn{2}{|c|}{ Groups } & \multirow{3}{*}{$x^{2}$} & \multirow{3}{*}{ value } & \multirow{3}{*}{$P$ value } \\
\hline & & $\begin{array}{c}\mathrm{A} \\
(\mathrm{n}=30)\end{array}$ & $\begin{array}{c}B \\
(n=30)\end{array}$ & & & \\
\hline & & (no $(\%)$ & no $(\%)$ & & & \\
\hline Normal (<100 IU/ml) & 1 & $28(93.3)$ & $6 \quad(20)$ & & 32.851 & $.001 * * *$ \\
\hline Elevated (>100 IU/ml) & & $2(6.7)$ & $24(80)$ & & & \\
\hline
\end{tabular}

Group A: Apparently healthy adults (Control)

Group B: Adults suffering from mild intermittent asthma( experimental)

$\mathrm{n}=$ number of subjects

Value in parenthesis indicates percentage

$\mathrm{df}=$ degree of freedom

$* * *=$ Significant at $<0.001$

Results of the frequency distribution of the subjects by SPT with elevated serum total IgE level are shown in figure 4. Percentages of positive SPT patients were significantly $(<0.001)$ higher than those of negative SPT patients with elevated serum total IgE level.

Again, association of the findings of positive skin prick test of different allergens with elevated serum total IgE level in asthmatic patients were studied. A non significant association were observed among them. No data are presented in this aspect.

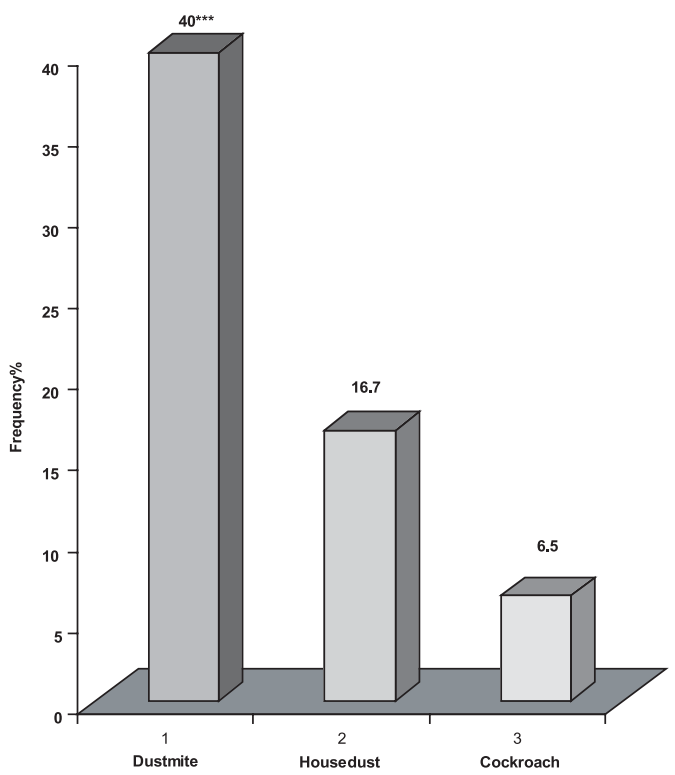

Figure 2. Distribution of the asthmatic patients by the findings of Skin Prick Tests $(n=30)$

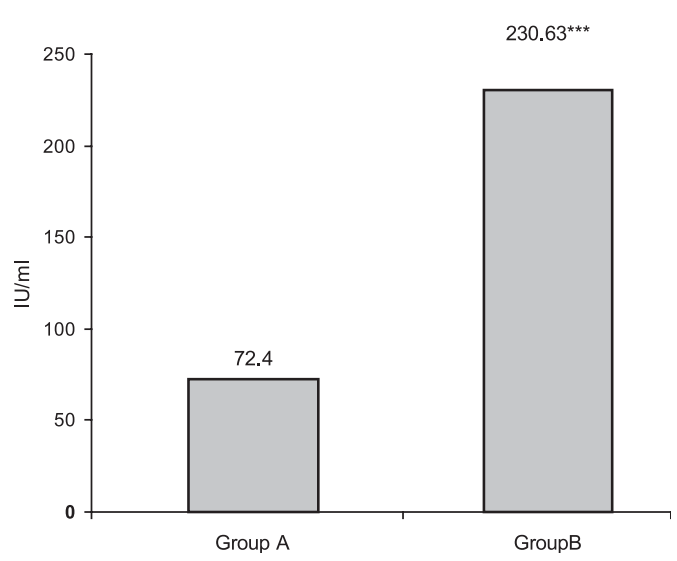

Figure 3. Showing mean of serum total IgE level in different study groups $(\mathrm{n}=60)$.

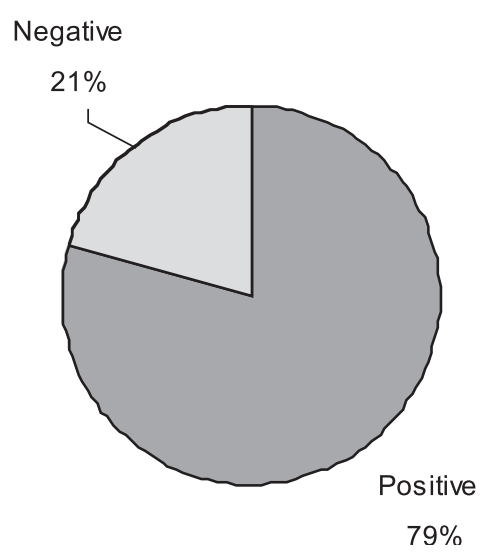

Figure 4. Distribution of Skin prick tests with elevated serum IgE level.

J Bangladesh Soc Physiol. 2009 June; 4(1): 1-6 


\section{Discussion}

In this study, skin prick tests were performed by using common indoor allergens like, house dust, dust mite and cockroach among asthmatic patients in order to detect type of allergens present in our population with bronchial asthma. Because of non availability, SPT for other allergens were not done. Although laboratory tests for serum total IgE level were done both in asthmatic and healthy subjects. .

In this study, maximum numbers of asthmatic patients had positive SPT for dust mite which was significantly higher than that of house dust and cockroach. Similar type of observations were made by many investigators of different countries including Bangladesh . 2,13,15-16, .

Significantly higher mean serum total IgE level was found in asthmatic adults compared to the healthy subjects. Similar observations were reported by some other investigators. ${ }^{17-18}$. In this study, there was association between the positive skin prick tests of all allergens and elevated serum total IgE though it was not statistically significant . Similar results were also observed..$^{12,19}$ Maximum numbers of asthmatic patients had elevated serum IgE level and a significant association was found between asthma and elevated srum IgE level .

Several mechanisms have been proposed about the allergens induced bronchoconstriction in bronchial asthma. It has been suggested that the inhalation of an allergen in a sensitized asthmatic patient results in two-phase bronchoconstrictor response, early and late. The inhaled allergen rapidly interacts with mucosal mast cells via an IgEdependent mechanism resulting in the release of mediators such as histamine and the cystinyl leukotriens which lead to bronchoconstriction. 3,10,14,18,19-20. The inhaled allergens initiate IgE-mediated reactions in the lung.They also suggested that following allergen exposure, helper T cells in asthmatic patients produce IL4,IL-5 and IL-13, which promote the synthesis and secretion of IgE from B cell and thereby elevated the serum IgE level .21-23

Therefore, this study revealed that different allergens like, house dust, dust mite and cockroach are responsible for bronchial asthma in our country which can be detected by SPT. Though only three indoor allergens were studied but other indoor allergens like, pet-derived allergens, molds including outdoor allergens like, industrial fumes, ozone, pollens, grass etc may have some important role in causing bronchial asthma. Because of non availablity of all the above mentioned allergens, it was not possible to include in this study. In addition presence of elevated serum total IgE level in SPT positive asthmatic patients also support these tests .

The above findings indicates that this test can be done along with SPT may be a useful measure for earlier detection of allergens .Accordingly hyposensitization or desensitization of that patients with those allergens may be the preventive and theraputic measures. All these measures can be adopted to minimize the risk of complications specially in young adults and thereby can improve their quality of life .

\section{Conclusion}

However, from the above findings it can be concluded that different allergens like, house dust, dust mite and cockroach are responsible for bronchial asthma in our country and dust mite is commonest. Presence of all these allergens can be detected by Skin prick tests. Thus skin prick tests can be used for identification of type of actual allergens responsible for bronchial asthma which may be a useful measure for earlier detection of allergens and for hyposensitization or desensitization of that patients accordingly with those allergens. 


\section{Article}

\section{Author Affiliations}

*1. Tasmina Parveen, Assitant Professor Department of Physiology,East-West Medical College , Dhaka, Bangladesh.

2. Noorzahan Begum, Professor Department of Physiology , Bangabandhu Sheik Mujib Medical University, Shahbag, Dhaka.

3. Shelina Begum, Professor and Chairman, Department of physiology , Bangabandhu Sheik Mujib Medical University, Shahbag, Dhaka.

*For Correspondence

\section{References}

1. Ganong WF. Respiratory adjustments in Health \& diseases, Review of Medical Physiology, 21st edition, New York, McGraw -Hill, Boston Burr Ridge .2003: pp.692-93.

2. Kelley W, Argyros G, Katial RK. Allergic and Environmental Asthma .http//www.e medicine.com/ med/topic 3390.htm.2004.

3. Bardana EJ. Jr. What Characterize allergic asthma ? Ann Allergy 1992; 68 (5) : 371-73.

4. Burrows B, Lebowitz MD, Barbee RA. Respiratory disorders and allergy skin test reactions. Ann Intern Med 1976 ; 84: 134.

5. Cotran RS, Kumar V, Robbins SL. Disease of Immunity. In: Robbins Pathologic Basis of Disease. $6^{\text {th }}$ ed. W.B. Saunders Company, United states of America, 1994 pp.195.

6. McFadden ER. Jr. Asthma, In: Issel bacher KJ, Brannwald E, Wilsonnnn JD, Martin JB, Fanci AS , Karper DL, editors, Harrison's Principles of Internal Medicine $13^{\text {th }}$ ed . New York : Mc Graw Hill , Inc; 2005 : pp. 1508-1515.

7. Tollerud DJ, O’ Connor GT, Sparrow D, Weiss St - Asthma , Hay fever and Phlegm production associated with distinct patterns of allergy skin test reactivity, eosinophilia and serum IgE levels. Am Rev Respir Dis 1991; 144 : 776-781.

8. Halonen M, Barbee RA, Lebowitz MD, Burrows B. An epidemiologic study of the interrelationships of total serum IgE , allergy skin test reactivity and eosinophilia. J Allergy Clin Immunol 1982; 69: 221-228.

9. Devenney I, Falth-Magnusson K, Skin prick test may give generalized allergic reactions in infants .Ann Allergy, Asthma \& Immunol 2000; 85 (6): 457-460.

10. Ulrik CS. Eosinophils and pulmonary function : An epidemiologic study of adolescents and young adults. Ann Allergy Asthma Immunol 1998 ; 80 : 487-93.

11. Arshad SH, Tariq SM, Mathews S, Hakim E. Sensitization to common allergens and its association with allergic disorders at age 4 years .Pediatrics 2001; 108(2): 1-8.
Allergen Skin Test Adult Bronchial Asthmatic Patients

12. Burrows B, Martinez F, Halonen M, Barbee RA, Clin MG. Association of asthma with serum IgE levels and skin test reactivity of allergens . N Engl J Med 1989 ; 320 : 271-76.

13. Gelber LE, Seltzer LH, Bouzoukis JK, Pollart SM, Chapman MD, platts Mills TAE, Sensitization and exposure to indoor allergens as risk factors for asthma among patients presenting to hospital . Am Rev Respir Dis 1993; 147: 573-78

14. Burrows B, Hasan FM, Barbee RA, Halonen M, Lebowitz MD. Epidemiologic observations on Eosinophilia and its relation to respiratory Disorder. Am Rev Respir Disease 1980; 122: 709-17.

15. Mondol EA , Rahman ASMM. Prevalence of Mite allergens amongst patients of Bronchial asthma. Bangladesh Armed Forces Medical Journal 2000;26: 41-45.

16. Celedon JC, Palmer LJ, Weiss ST ,Wang Binyan , Fang Z, Xu X . Asthma, Rhinitis and Skin test reactivity to Aeroallergens in families of asthmatic subjects in Anquing, China . Am. J. Respir. Crit. Care. Med 2001; 163(5): 1108-1112.

17. Laprise C, Boulet LP.Airway responsiveness and atopy in families of patients with asthma .Clin Invest Med 1996; 19(60): 461-469.

18. Erikson NE, Moller C, Wihl JA ,Zolubas M. Skin prick tests and IgE determination with common inhalant I allergens, inhalant insect allergens and shrimp relationships to indoor environment. Concomitant sensitization to different allergens .Vaiku Pulmonologija IR Alargologija, 2000;3.

19. Jansen DF, Rijcken B, Schouten et al . The relationships of skin test positivity, high serum IgE level and Peripheral blood eosinophilia to symptomatic and asymptomatic airway hyperresponsiveness. Am J Respir Crit Care Med 1999;159(3): 924-931.

20. Lewis SA, Pavord ID, Stringer JR et al . The Relation between peripheral blood leukocyte counts and respiratory symptoms, atopy, lung function and airway responsiveness in adults. Chest 2001; 119: $105-114$

21. Gleich GJ, Flavanhan NA, Fuji Sava T, Van-houlte M. The eosinophil as a mediator of damage to respiratory epithelium: a model for bronchial hyperreactivity .J. Allergy Clin . Immunol 1988; 81: 776-781.

22. Wardlaw AJ, Dunnette S, Gleich GJ, Collins JV and Kay AB. Eosinophils and mast cells in bronchoalveolar lavage in subjects with mild asthma : relationship to bronchial hyperreactivity . Am. Rev.Respir.Dis 1988; 137: 62-69.

23. Roitt I, Brostoff J, Male D. hypersensitivity - Type 1 . Immunology, $5^{\text {th }}$ edi, Harcourt Brace and company, Asia PTE Ltd .Mosby- Year book, Inc.USA 1999: pp 301- 317.

J Bangladesh Soc Physiol. 2009 June; 4(1): 1-6 